\title{
Comparative Proteomics for Identification of Reproduction- Related Proteins in Testes of the Giant Tiger Shrimp Penaeus monodon
}

\author{
Sirawut Klinbunga ${ }^{1, *}\left(\mathbb{D}\right.$, Sasithorn Petkorn ${ }^{2}$, Narumon Phaonakrop ${ }^{1}$, Sirithorn \\ Janpoom ${ }^{1}$, Sirikan Prasertlux ${ }^{1}$, Puttawan Rongmung ${ }^{1}$, Sittiruk Roytrakul ${ }^{1}$, Piamsak \\ Menasveta $^{3}$, Bavornlak Khamnamtong ${ }^{1}$
}

\footnotetext{
${ }^{1}$ National Science and Technology Development Agency, National Center for Genetic Engineering and Biotechnology (BIOTEC), Khlong Nueng, Khlong Luang, Pathum Thani 12120, Thailand.

${ }^{2}$ Chulalongkorn University, Program in Biotechnology, Faculty of Science, Bangkok 10330, Thailand.

${ }^{3}$ The Royal Society of Thailand, Academy of Science, Bangkok 10300, Thailand.
}

\section{Article History}

Received 15 January 2020

Accepted 04 August 2020

First Online 18 August 2020

\section{Corresponding Author}

Tel.: +6626448150

E-mail: sirawut@biotec.or.th

\section{Keywords}

Proteomics

Penaeus monodon

Gene expression

Srpk3

Testicular development

\begin{abstract}
Testicular proteome of wild and domesticated 14- and 18-month-old broodstock of the giant tiger shrimp Penaeus monodon was examined. Among 344 differentially expressed proteins identified, 11 proteins (e.g. p97/VCP-binding protein p135, lipoxygenase homology domains 1 and dipeptidyl-peptidase, accounting for $4.95 \%$ of proteins with known functions) were found in wild broodstock but not in domesticated broodstock while 152 (68.47\%) proteins were commonly found in all groups of samples. Reproduction-related proteins such as vasa-like protein, Wee1-like protein kinase, serine/threonine protein kinase, mitogen activated protein kinase kinase 2, GTP-binding protein alpha subunit, seven membrane helix receptor, nuclear receptor subfamily 3 , were identified. To examine a possible role of the signal transduction system in development of testes of $P$. monodon, the expression level of testicular serine/arginine rich-protein kinase 3 (PmSrpk3) mRNA of domesticated juveniles and broodstock was examined and it was significantly lower than that of wild $P$. monodon broodstock $(\mathrm{P}<0.05)$. PmSrpk3 expression was significantly induced by serotonin $(P<0.05)$ but not progesterone $(P>0.05)$ injection. The expression profiles of PmSrpk3 indicated reduced reproductive maturation of domesticated male $P$. monodon and exogenous administration of serotonin may be applied for promoting the testicular development of captive $P$. monodon
\end{abstract}

\section{Introduction}

The giant tiger shrimp Penaeus monodon is an economically important species (Klinbunga et al., 2001; Rosenberry, 2003; Clifford and Preston, 2006). Farming of $P$. monodon in Thailand relies almost entirely on wildcaught broodstock for supply of juveniles because of poor reproductive maturation of pond-reared P. monodon (Withyachumnarnkul et al., 1998; Preechaphol et al., 2007). This issue is one of crucial problems for sustainability of the shrimp farming industry (Leelatanawit et al., 2017). In addition, reduced reproductive maturation in cultured $P$. monodon have limited the ability to selectively improve or maintain important genetic traits in this species.

The production of $P$. monodon is largely constrained by the current dependency on wild-caught broodstock which varies in both quality and quantity (Klinbunga et al., 2012; Leelatanawit et al., 2009; Preechaphol et al., 2007). The domestication and selective breeding programs of this species would provide a more reliable supply of juveniles and improvement of the production efficiency (Makinouchi and Hirata, 1995; Clifford and Preston, 2006; Coman et 
al., 2006). The use of selectively bred stocks having improved culture performances on commercially desired traits rather than the reliance on wild-caught stocks is a major mean of sustainability of the shrimp industry (Benzie, 1998; Clifford and Preston, 2006; Coman et al., 2006). Nevertheless, genetic improvement of $P$. monodon is slow owing to the lack of the basic information related with its gonad development and maturation.

The information related to testicular development and sperm quality in penaeid shrimp is rather limited. Accordingly, an initial step towards understanding molecular mechanisms of testicular development in $P$. monodon is identification and characterization of reproduction-related genes/proteins expressed in testes of this economically important species.

Proteomic analysis is a powerful and widely used method for identification of differential expressed proteins. Proteomics also provide the basic information on post-translational modification of interesting proteins which cannot be inferred from genomic and transcriptomic analyses. This information is important for understanding molecular mechanisms controlling testicular development of $P$. monodon. Here, protein profiles in testes of wild and domesticated $P$. monodon broodstock were identified by GeLC-MS/MS. Expression of serine/arginine-rich protein kinase 3 (PmSrpk3) which play a role in a signal transduction pathway, in testes of wild and different ages of domesticated shrimp was determined. Effects of serotonin (5-HT) and progesterone on its expression in domesticated 18month-old broodstock were also examined. The information obtained allows better understanding of the reproductive maturation of male $P$. monodon in captivity.

\section{Materials and Methods}

\section{Sampling}

For proteomics based on one-dimensional gel electrophoresis (SDS-PAGE) and nano-electrospray ionization-LC-MS/MS (nanoESI-LC-MS/MS), wild male P. monodon broodstock $(N=6$, average body weight $=122.11 \pm 7.15$; gonadosomatic index, $\mathrm{GSI}=0.67 \pm 0.09 \%$ ) were collected and further divided to two groups according to the SDS-PAGE protein patterns ( $N=3$ for each group with the average body weight of $123.55 \pm 9.36 \mathrm{~g}, \mathrm{GSI}=0.66 \pm 0.18 \%$ for group $\mathrm{A}$ and average body weight of $120.67 \pm 11.09 \mathrm{~g}, \mathrm{GSI}=0.68 \pm 0.09 \%$ for group $\mathrm{B}$, respectively). In addition, domesticated broodstock: 14-month-old ( $N=3$, average body weight $=69.84 \pm 2.76 \mathrm{~g}$ and $\mathrm{GSI}=0.37 \pm 0.03 \%$ for group $\mathrm{C}$ ) and 18- month- old $(N=3$, average body weight $=82.18 \pm 2.88 \mathrm{~g}$ and $\mathrm{GSI}=0.37 \pm 0.01 \%$ for group $\mathrm{D}$ ) were also included in the experiment.

For expression analysis of PmSrpk3 mRNA, male domesticated $P$. monodon juveniles ( $N=3$, average body weight $=37.80 \pm 1.85 \mathrm{~g}, 6$-month-old) and broodstock: 10 - month-old ( $N=3$, average body weight $=51.24 \pm 3.27 \mathrm{~g})$, 14 -month-old $(N=4$, average body weight $=62.40 \pm 3.87$ $\mathrm{g})$, and 18-month-old $(N=5$, average body weight $=74.10 \pm 4.28 \mathrm{~g})$ and wild broodstock $(N=5$, average body weight $=126.16 \pm 10.75 \mathrm{~g}$ ), were analyzed. Testes were dissected out from each shrimp, placed in liquid $\mathrm{N}_{2}$ and kept at $-80^{\circ} \mathrm{C}$ until needed.

To examine effects of serotonin (5-HT) on expression of PmSrpk3, domesticated 18-month-old $P$. monodon males (average body weight of $74.18 \pm 1.85 \mathrm{~g}$, $N=40$ ) were sampled and acclimated for 7 days at the laboratory conditions $\left(28-30^{\circ} \mathrm{C}\right.$ and $30 \mathrm{ppt}$ seawater under natural daylight) in 500-liter aquaria. Eight groups of female shrimp were injected intramuscularly into the first abdominal segment with $5-\mathrm{HT}(50 \mu \mathrm{g} / \mathrm{g}$ body weight; the working solution $=25 \mu \mathrm{g} / \mu \mathrm{l}$ in $0.85 \% \mathrm{NaCl}$ ). Specimens were collected at 0, 0.5, 1, 3, 6, 12, 24, 48 and $72 \mathrm{~h}$ post injection (hpi). Shrimp injected with the $0.85 \%$ saline solution (at $0 \mathrm{hpi}$ ) were included as the vehicle control (VC).

Moreover, four groups of acclimated domesticated male shrimp (18-month-old; average body weight of $67.37 \pm 2.14 \mathrm{~g}, N=20$ ) were injected intramuscularly into the first abdominal segment with progesterone $(0.1$ $\mu \mathrm{g} / \mathrm{g}$ body weight; the working solution $=1 \mu \mathrm{g} / \mu \mathrm{l}$ in absolute ethanol). Specimens were collected at 12, 24, and $72 \mathrm{hpi}$. Uninjected shrimp (at $0 \mathrm{hpi}$ ) and those injected with absolute ethanol (at $12 \mathrm{hpi}$ ) were included as the negative (NC) and vehicle (VC) controls, respectively. Procedures for animal use in the present study were performed according to the regulation of the Institutional Animal Care and Use Committee (IACUC) of National Center for Genetic Engineering and Biotechnology (BIOTEC).

\section{Total Protein Extraction, Size Fractionation and Mass} Spectrometry

Approximately $50 \mathrm{mg}$ of frozen testes of $P$. monodon was ground to the fine powder in the presence of liquid $\mathrm{N}_{2}$, suspended in $500 \mu \mathrm{l}$ of $10 \%(\mathrm{w} / \mathrm{v})$ trichloroacetic acid in acetone (TCA) containing $0.1 \%$ dithiothreitol (DTT) and left at -20 o C for $1 \mathrm{~h}$. The homogenate was centrifuged at $10000 \mathrm{~g}$ for $10 \mathrm{~min}$ at $4^{\circ} \mathrm{C}$. The supernatant was collected. An equal volume of $10 \%$ TCA was added and left at $-20{ }^{\circ} \mathrm{C}$ overnight. The mixture was centrifuged at $10000 \mathrm{~g}$ for $30 \mathrm{~min}$ at $4^{\circ} \mathrm{C}$. The supernatant was discarded and the pellet was washed in acetone containing $0.1 \%$ DTT. The sample was centrifuged at $10000 \mathrm{~g}$ for $30 \mathrm{~min}$ at $4^{\circ} \mathrm{C}$. The pellet was air-dried and dissolved in the lysis buffer (30 mM Tris$\mathrm{HCl}, 2 \mathrm{M}$ Thiourea, $7 \mathrm{M}$ Urea, 4\% CHAPS, w/v). The total amount of extracted proteins was measured using a modification of Lowry's method (Peterson, 1977). The extracted proteins $(10 \mu \mathrm{g})$ from wild and captive broodstock were size-fractionated by $12.5 \%$ SDS-PAGE (Laemmli, 1970) using a low molecular weight protein standard marker (Bio-Rad) to estimate protein sizes. At the end of each run, the protein gels were silver-stained. 
The protein bands were excised according to marker proteins ranges (>225, 176-225, 150-176, 102-150, 76$102,52-76,38-52$ and $<38 \mathrm{kDa}$ ) and $4-5$ pieces of approximately $1 \mathrm{~mm}^{2}$ gel slices were subjected to in-gel digestion with $20 \mu \mathrm{l}$ of a trypsin solution $(10 \mathrm{ng} / \mu \mathrm{l}$ trypsin in $50 \%$ acetonitrile/10 $\mathrm{mM}$ ammonium bicarbonate). The protein digest was injected into an Ultimate 3000 LC System (Dionex, USA) coupled to an ESI-Ion Trap MS (HCT Ultra PTM Discovery System, Bruker, Germany) with electrospray at a flow rate of 300 $\mathrm{nl} / \mathrm{min}$ to a nanocolumn (Acclaim PepMap $100 \mathrm{C} 18,3$ $\mu \mathrm{m}, 100 \mathrm{~A}, 75 \mu \mathrm{m}$ inside diameter $\times 150 \mathrm{~mm}$ ). A solvent gradient (solvent $A: 0.1 \%$ formic acid in water; solvent $B$ : $80 \%$ acetonitrile in $0.1 \%$ formic acid) was run in $40 \mathrm{~min}$.

\section{Database Search and Quantitation of Characterized Proteins}

After data acquisition, MS/MS ions from nanoLCMS/MS were analyzed using DeCyder MS Differential Analysis software (DeCyderMS, GE Healthcare) for quantitative protein analysis (Johansson et al., 2006; Thorsell et al., 2007). Acquired LC-MS raw data were converted and the PepDetect module was used for automated peptide detection, charge state assignments, and quantitation based on the peptide ions signal intensities in MS mode. The analyzed MS/MS data from DeCyderMS were subjected to database searches using Mascot software (Matrix Science, London, UK; Perkins et al., 1999) against data of the P. monodon database (http://pmonodon.biotec.or.th), the NCBI nonredundant protein sequence database (nr; http://www.ncbi.nih.gov) and the SWISSPROT database (http://expasy.org/) for protein identification. Database interrogation selections included taxonomy (all entries), enzyme (trypsin), variable modifications (carbamidomethyl, C or oxidation of methionine residues, $\mathrm{M}$ ), mass values (monoisotopic), protein mass (unrestricted), peptide mass tolerance (1.2 Da), fragment mass tolerance $( \pm 0.6 \mathrm{Da})$, peptide charge state $(1+, 2+$ and $3+)$ and max missed cleavages (1). Proteins were considered matched if at least two peptides were found with an individual mascot score corresponding to $\mathrm{P}<0.05$ and $\mathrm{P}<0.1$, respectively.

\section{RT-PCR and Tissue Distribution Analysis}

Expression of PmSrpk3 (F: 5'ATGGTGTTTGAAGTGCTGGGTC-3' and R: 5'CTTATGAGGCAACCCAGTGGC-3') and EF- $1 \alpha_{500}$ (F: 5'ATGGTTGTCAACTTTGCCCC- $3^{\prime}$ and R: $5^{\prime}$ TTGACCTCCTTGATCACACC- $3^{\prime}$ ) in various tissues of wild male broodstock and ovaries of female broodstock were analyzed by RT-PCR. The thermal profiles were predenaturation at $94^{\circ} \mathrm{C}$ for $3 \mathrm{~min}$ followed by 30 cycles of $94^{\circ} \mathrm{C}$ for $30 \mathrm{~s}, 53^{\circ} \mathrm{C}$ for $45 \mathrm{~s}$ and $72^{\circ} \mathrm{C}$ for $30 \mathrm{~s}$. The final extension was carried out at $72^{\circ} \mathrm{C}$ for $7 \mathrm{~min}$. Five microliters of the amplification product was analyzed by $1.5 \%$ agarose gel electrophoresis.

\section{Quantitative Real-Time PCR}

Standard curves representing $10^{3}-10^{8}$ copies of recombinant plasmids of PmSrpk3 (Primers PmSrpk3$\mathrm{F} / \mathrm{R}$ ) and the internal control, $E F-1 \alpha_{214}$ (F: 5'TCCGTCTTCCCCTTCAGGACGTC-3' and R: ${ }^{\prime}$ 'CTTTACAGACACGTTCTTCACGTTG-3'), were constructed. Each concentration was carried out in triplicate. The expression of PmSrpk3 and EF-1 $1 \alpha_{214}$ in ovaries of each shrimp was amplified in a $10 \mu$ reaction volume containing $5 \mu \mathrm{l}$ of $2 \mathrm{x}$ LightCycler 480 SYBR Green I Master (Roche), $300 \mathrm{ng}$ (target) or $10\left(E F-1 \alpha_{214}\right) \mathrm{ng}$ the first strand cDNA template, $0.2 \mu \mathrm{M}$ each primer. The thermal profile for quantitative real-time PCR was $95^{\circ} \mathrm{C}$ for $10 \mathrm{~min}$ followed by 40 cycles of $95^{\circ} \mathrm{C}$ for $15 \mathrm{~s}, 55^{\circ} \mathrm{C}$ for $30 \mathrm{~s}$ and $72^{\circ} \mathrm{C}$ for $30 \mathrm{~s}$. Real-time PCR of each specimen was carried out in duplicate. The relative expression level of PmSrpk3 and EF-1 $\alpha_{214}$ mRNA of each specimen was evaluated from their standard curves. The relative expression level (copy number of PmSrpk3 and $\left.E F-1 \alpha_{214}\right)$ between different groups of domesticated male shrimp ( $N=4$ each of $6,10-, 14$ - and 18-month-old), wild $(N=4)$, domesticated 18-month-old shrimp in serotonin injection (vehicle control, VC and 0.5, 1, 3, 6, 12, 24 and $48 \mathrm{hpi} N=4$ for each group), and domesticated 18-month-old shrimp in progesterone injection (negative control, NC and VC and 12, 24 and 72 hpi; $N=4$ for each group), were calculated.

\section{Statistical Analysis}

The relative expression levels of PmSrpk3 between male shrimp possessing different stages of testicular development and those in different groups in serotonin and progesterone injection were statistically tested using one-way analysis of variance (ANOVA) and Duncan's new multiple range test $(P<0.05)$. Results were considered significant when $\mathrm{P}<0.05$.

\section{Results}

\section{Size-fractionation of testicular proteins by SDS-PAGE and peptide sequencing by nanoESI-LC-MS/MS}

Total proteins from testes of each shrimp were analyzed by $12.5 \%$ SDS-PAGE. The electrophoresed bands were visualized by silver staining (Figure 1). Electrophoretic patterns of size-fractionated testicular proteins of wild shrimp were separated to two groups ( $A$ and $\mathrm{B}$ ). Total soluble proteins of $P$. monodon testes were further analyzed using nanoESI-LC-MS/MS. The intensity of the protein spectrum from testes of wild broodstock group A was used to normalize that of other sample groups. A few thousands of different proteins were identified and approximately 50 proteins that showed differential (up-regulation and down-regulation) expression profiles among sample groups for each molecular weight range were annotated (Supplementary Table 1). 


\section{Protein Annotation and Functional Classification}

In total, 344 differentially expressed proteins were annotated. Of these, 222 (64.53\%) significantly matched known proteins in the database and 122 (35.47\%) proteins did not match any protein in the NCBI database and were considered as unknown proteins (Supplementary Table 1). Interestingly, 11 proteins (e.g. p97/VCP-binding protein p135, lipoxygenase homology domains 1, dipeptidyl-peptidase, SEParase family member, euchromatic histone-lysine $\mathrm{N}$ methyltransferase and gravin; 4.95\%) were found in both groups $A$ and $B$ of wild broodstock but not in domesticated broodsotck while 152 (68.47\%) known proteins were commonly found in all groups of samples (Figure 2 and Supplementary Table 1).
Several proteins seem to be more abundantly expressed in domesticated broodstock than wild broodstock. They were, for example, kinesin like protein 67a, RUN domain containing 2A, GPBP-interacting protein $130 \mathrm{~b}$ and brain cyclic nucleotide gated 1 . In contrast, proteins that the expression level seems to be decreased in domesticated broodstock were, for instance, zinc finger protein 184, glutathione Stransferase alpha 1 , seven transmembrane helix receptor, cortactin-binding protein 2, nuclear receptor subfamily 3, group C, member 2 and syntaxin 5 (Supplementary Table 1).

Known proteins in this study were further categorized according to the biological functions of their homologues using the Gene Ontology Categorizer (GoCat software) and 222 differentially expressed
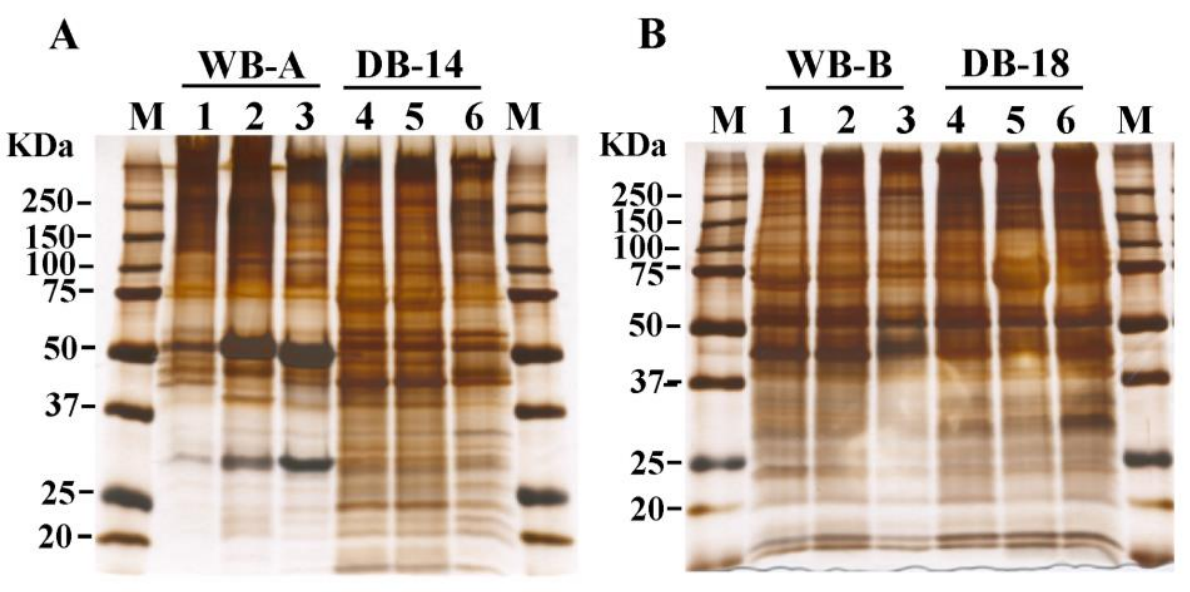

Figure 1. A 12.5\% SDS-PAGE showing expression patterns of testes of wild broodstock pattern A (lanes 1-3, panel A) and domesticated 14-month-old (lanes 4-6, panel A), wild broodstock pattern B (lane 1-3, panel B) and domesticated 18-month-old (lanes 4-6, panel B). Lanes $\mathrm{M}$ is the protein marker.

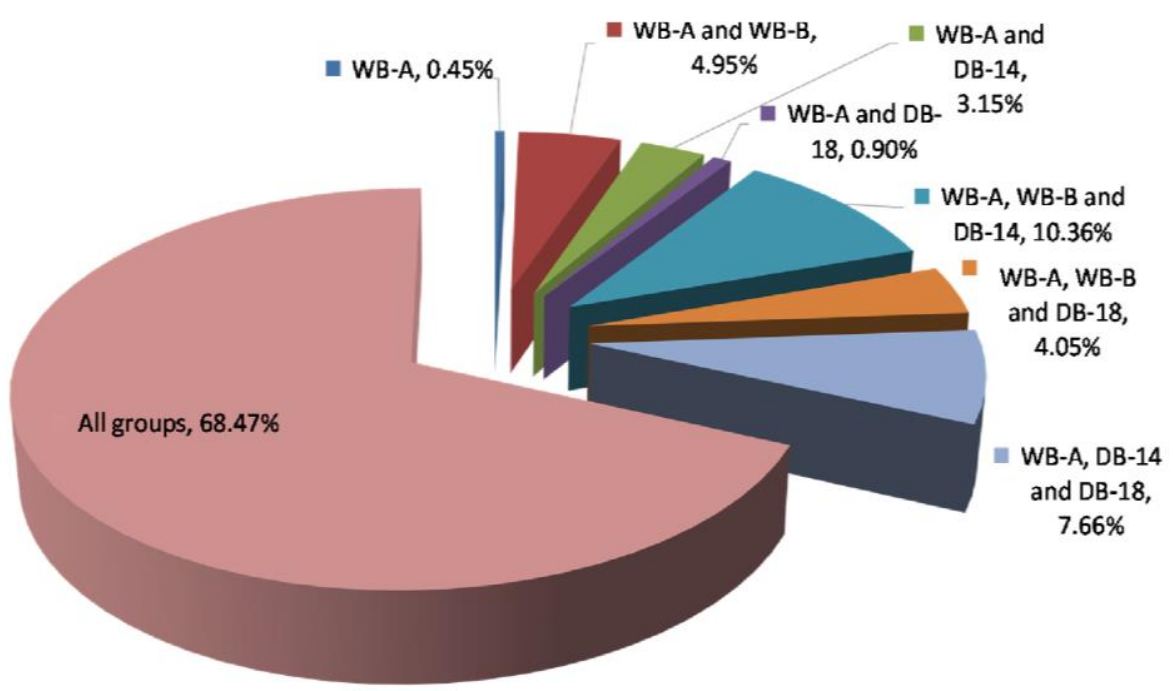

Figure 2. Functional classifications of 345 proteins identified form testes of wild (groups A and B; WB-A and WB-B) and domesticated (14- and 18-month-old; DB-14 and DB-18) P. monodon broodstock. 
proteins identified in testes of wild and domesticated broodstock of $P$. monodon were able to be classified to 11 functional categories (Figure 3).

These included transport and binding proteins (57 proteins accounting for $16.57 \%$; e.g. arginine kinase 2 , brain cyclic nucleotide gated 1 , asparagine-rich antigen, deltex 2 and DNA methyltransferase), cell division/DNA synthesis, repair and replication (41 proteins accounting for $11.92 \%$; e.g. zinc finger protein 184, zinc finger RNA binding protein, transcription factor 25, serine/threonine protein kinase and RUN domain containing 2A), signal transduction (36 proteins accounting for $10.47 \%$; e.g. Ran GTPase activating protein 1, vomeronasal type-1 receptor 1, F-box A protein family member fbxa-218, protein tyrosine phosphatase 99A CG2005-PB isoform B and GTP-binding protein alpha subunit gna), structural protein (27 proteins accounting for $7.85 \%$; e.g. calmodulinregulated giantin, chromosome-associated kinesin KIF4A, dynamin and circadian clock protein PER3), metabolic process (22 proteins accounting for $6.40 \%$; e.g. fatty-acid amide hydrolase, ATP synthase subunit alpha mitochondrial precursor, ATPase, $\mathrm{H}^{+}$transporting, lysosomal V0 subunit A2, glutathione S-transferase alpha 1 and phosphate transporter), defense and homeostasis (11 proteins accounting for 3.20\%; e.g. collagen type IV CG4145-PA isoform A, peptidoglycan recognition protein-lc, immunity-related GTPase $M 9$, ectonucleoside triphosphate and intersectin long isoform 1), oxidation-reduction (8 proteins accounting for $2.33 \%$ including 2,4-dichlorophenol hydroxylase, cytochrome P450 family 4 subfamily A polypeptide 11 ,
NADPH oxidase 4, NADH dehydrogenase Fe-S protein 1 $75 \mathrm{kDa}$ precursor isoform 1, oxidoreductase, short chain dehydrogenase/reductase family protein, CG4009 and GH16376), RNA processing (8 proteins accounting for $2.03 \%$ including nuclear cap-binding protein subunit 1 , nucleoporin 133, glutamyl-tRNA synthetase, glutamyltRNA cleavage and polyadenylation specificity factor 1 , initation factor $4 \mathrm{~B}$ and sfrs8 protein), biosynthetic process (7 proteins accounting for $2.03 \%$ including. 5 nucleotidase, dedicator of cytokinesis family protein , GI13543, guanylate cyclase, phosphoribosylformylglycinamidine synthase isoform CRA_a, midasin homolog and regulatory solute carrier protein, family 1 , member 1 ), catabolic process (4 proteins accounting for $1.16 \%$ including Uba1a protein, WW and C2 domain containing 2, inositol polyphosphate-4-phosphatase, type II and ubiquitin specific peptidase 38 ), chaperone (2 proteins accounting for $0.58 \%$ including heat shock $40 \mathrm{kDa}$ protein 1 and GL21472), respectively (Figure 3 and Supplementary Table 1).

Tissue distribution and expression of serine/arginine rich protein-specific kinase $\mathbf{3}$ (PmSrpk3) in ovaries and testes of $P$. monodon

Serine/threonine protein kinases were identified in our previous (based on 2-DE and nanoESI-LC-MS/MS; Klinbunga et al., 2012) and present (based on Gel-LC$\mathrm{MS} / \mathrm{MS}$ ) studies. In addition, the partial cDNA sequence of PmSrpk3 (also called serine/threonine-protein kinase 23, Stpk23) transcript was initially identified from EST

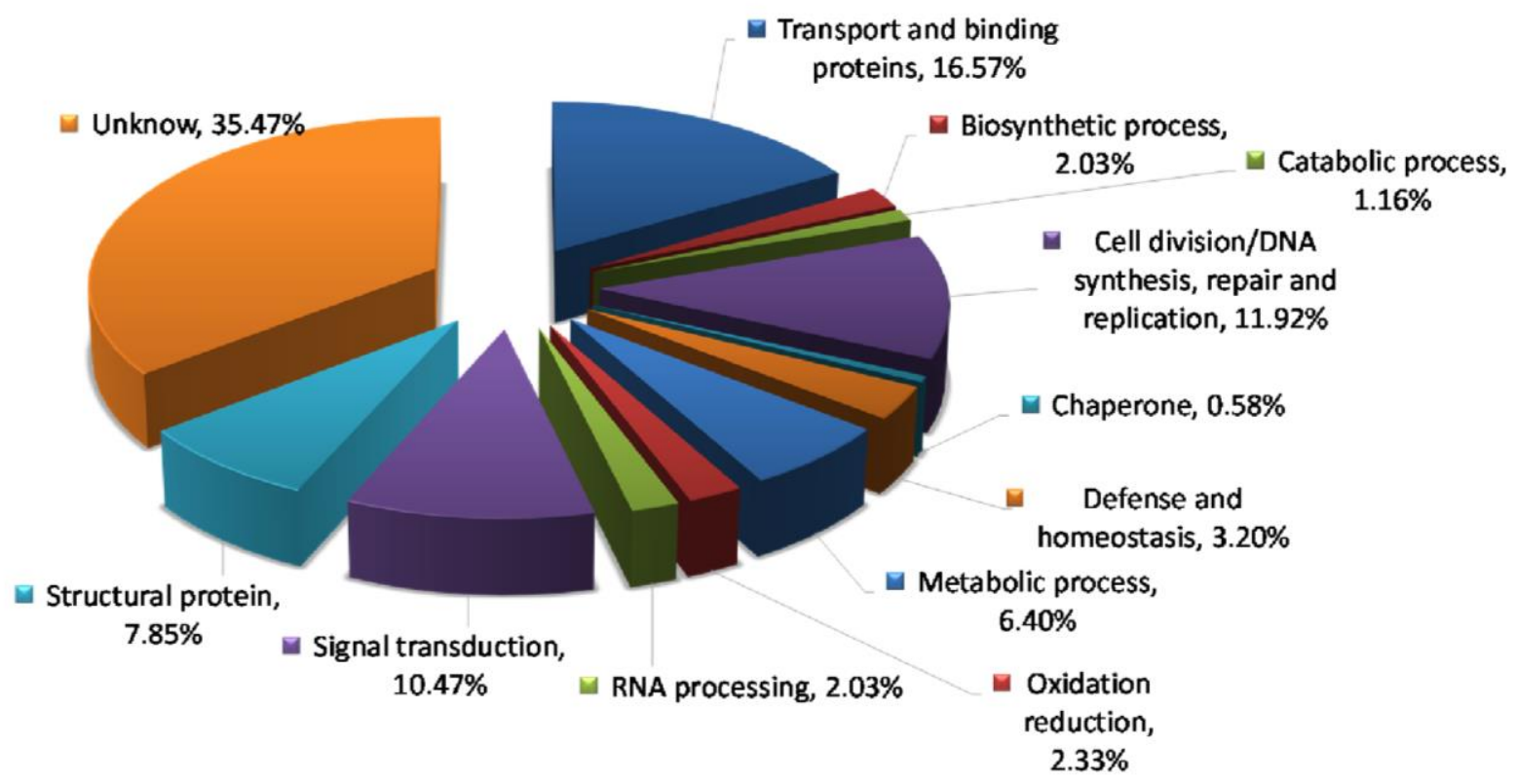

Figure 3. Categorized classifications of 345 proteins identified form testes of different groups of samples (wild broodstock groups $\mathrm{A}$ and $\mathrm{B}$, and domesticated 14-month-old and 18-month-old boodstock) of $P$. monodon. 
analysis (clone no. TT-N-S01-0903-N, Leelatanawit et al., 2009). It significantly matched serine/threonine-protein kinase 23, Stpk3 of Apis mellifera (E-value=4e-90). Therefore, expression profiles of PmSrpk3 was chosen to examine for demonstration of the contribution of serine/threonine protein kinase genes on testicular development of $P$. monodon.

At the transcriptional level, PmSrpk3 was constitutively expressed in all examined tissues of $P$. monodon broodstock and its expression was more preferentially expressed in ovaries than testes of $P$. monodon juveniles and broodstock (Figure 4).

\section{Expression Profiles of PmSrpk3 in Different Stages of Testicular Development of $\boldsymbol{P}$. monodon}

The expression level of PmSrpk3 in 6-month-old juveniles was not significantly different from that in 10- , 14- and 18-month-old shrimp ( $P>0.05)$ but its expression in testes of domesticated shrimp was significantly lower than from that of wild broodstock $(P<0.05)$ (Figure 5$)$.

\section{Effects of Exogenous Progesterone and 5-HT Injection on Expression Levels of PmSrpk3}

The expression levels of PmSrpk3 in testes of domesticated 18-month-old $P$. monodon was not significantly induced by progesterone injection. Although its expression levels in shrimp at $72 \mathrm{hpi}$ seemed to be higher than that in the negative and vehicle controls, the results were not significant owing to large standard deviation between groups of samples ( $P>0.05$ ) (Figure 6A).
In contrast, the expression level of PmSrpk3 in testes of domesticated $P$. monodon (18-month-old) upon injecting with serotonin (5-HT) for $1 \mathrm{~h}$ was significantly greater than that of the vehicle control (at 0 hpi). Its expression level at other time-intervals seemed to be greater but was not significantly different from the control $(\mathrm{P}>0.05)$ (Figure 6B).

\section{Discussion}

Comparative Proteomics for Isolation of Differentially Expressed Proteins in Testes of $\boldsymbol{P}$. monodon

Due to difficulties in reproductive maturation of captive $P$. monodon, molecular mechanisms of this process have long been of interest by aquaculture industry (Preechaphol et al., 2007). Isolation and characterization of reproduction-related genes in testes of $P$. monodon have been reported based on express sequence tag (EST), suppression subtractive hybridization (SSH) (Leelatanawit et al., 2004; 2008 and 2009; Wongsurawat et al., 2010) and transcriptomic (Uengwetwanit et al., 2018) analyses. More direct information of molecules functioned on testicular development of $P$. monodon can be obtained based on cellular proteomics. However, data on reproductionrelated proteins in testes of $P$. monodon is still limited.

In our previous study, typical 2-DE gel electrophoresis and nanoESI-LC-MS/MS was applied for isolation and characterization of protein profiles in testes of wild (GSI $=1.08 \pm 0.18 \%, N=3$ ) and domesticated (GSI=0.37 $\pm 0.05 \%, N=3$ and $\mathrm{GSI}=0.31 \pm 0.05 \%, \quad N=3$ ) broodstock of $P$. monodon. In total, 642 protein spots

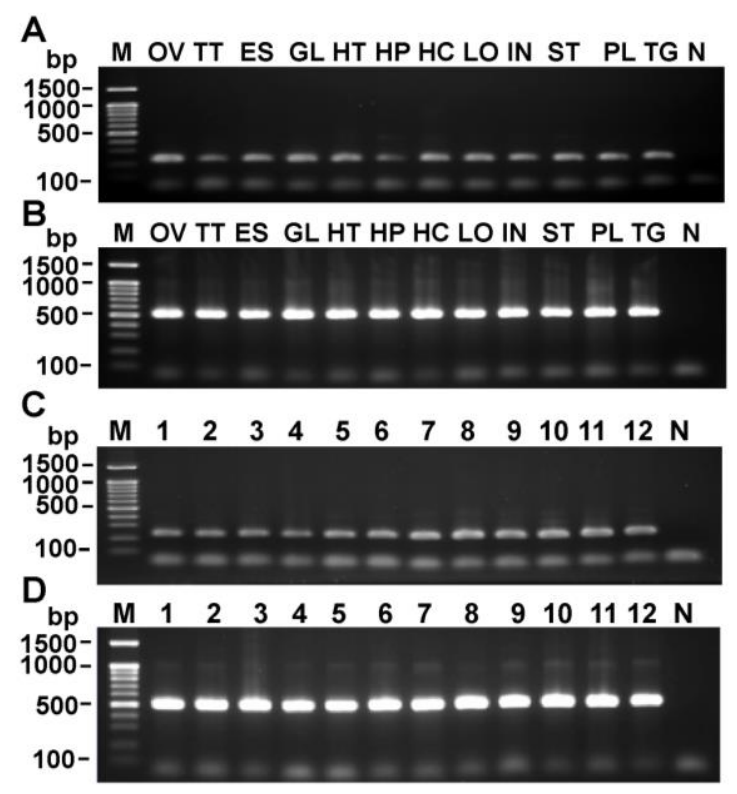

Figure 4. Expression of PmSrpk3 in different tissues (A) was carried out using the cDNA template from ovaries (OV), testes (TT), eyestalks (ES), gills (GL), heart (HT), hepatopancreas (HP), hemocytes (HC), lymphoid organs (LO), intestine (IT), stomach (ST), pleopods (PL), and thoracic ganglion (TG). RT-PCR (C) of PmSrpk3 using the first-strand CDNA of testes of wild broodstock (lanes 1-3, C) and domesticated juveniles (lanes 4-6, C) and ovaries of wild broodstock (lanes 7-9, C) and domesticated juveniles (lanes 10-12, C) of $P$. monodon. $E F-1 \alpha$ (B and $\mathrm{D}$ ) amplified from the same template was included as the positive control. 


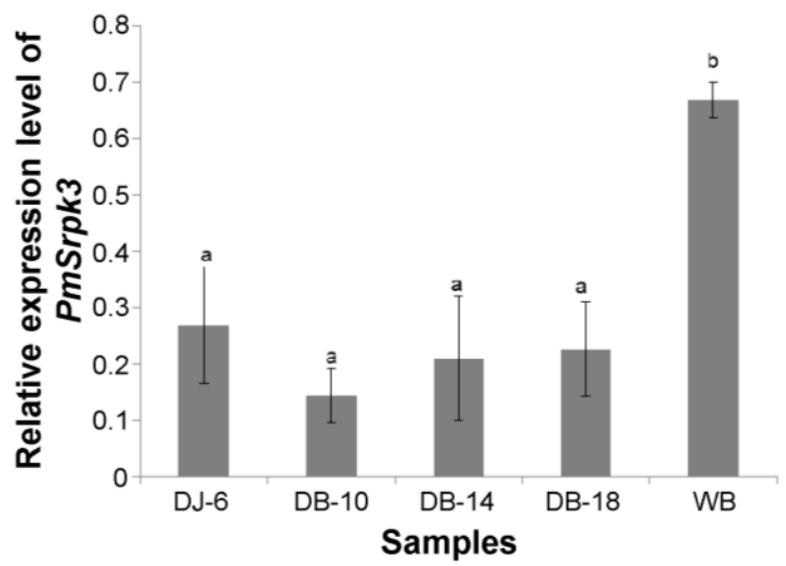

Figure 5. Histograms showing relative expression levels of PmSrpk3 during testes development of 6-month-old male juveniles (DJ-6), and 10-month-old (DB-10), 14-month-old (DB-14) and 18-month-old (DB-18) domesticated male broodstock and wild (WB) male broodstock of $P$. monodon.

A

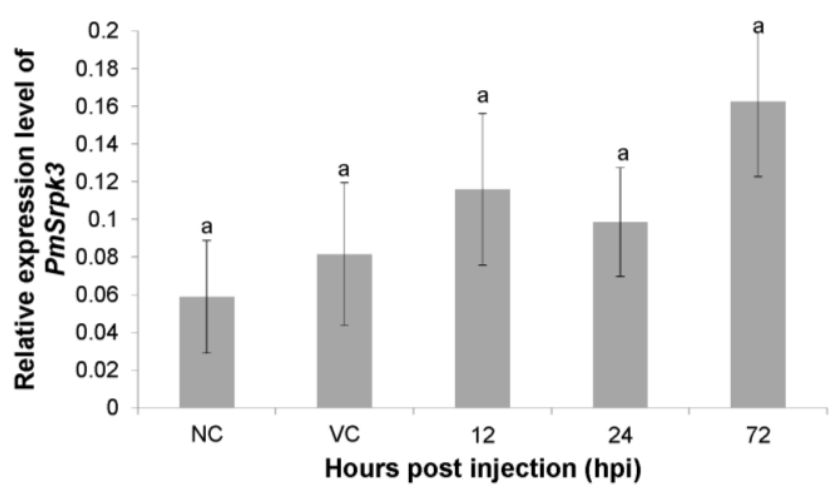

B

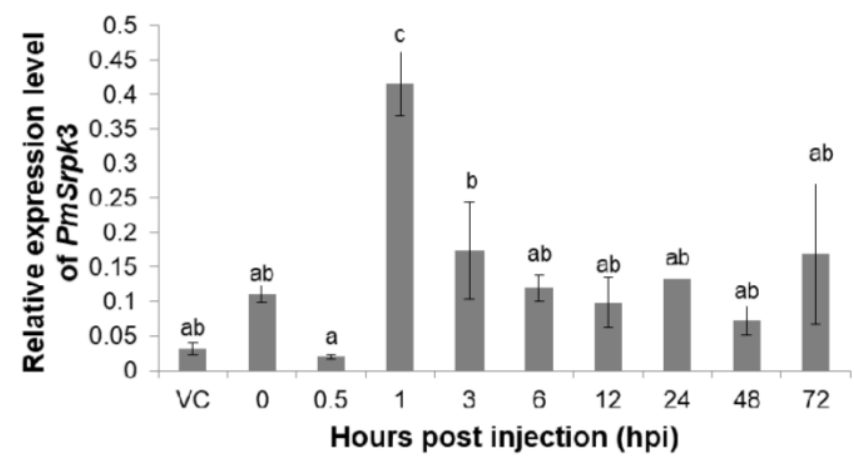

Figure 6. (A) Mean relative expression levels of PmSrpk3 in testes of domesticated 18-month-old shrimp injected with progesterone and assessed at 12,24 , and $72 \mathrm{hpi}(0.1 \mu \mathrm{g} / \mathrm{g}$ body weight; 18 -month-old, $N=4$ for each group). $\mathrm{VC}=$ shrimp injected with absolute ethanol at $12 \mathrm{hpi}$ (vehicle control). Acclimated shrimp without any treatment were included as the negative control (NC). (B) Timecourse relative expression levels of PmSrpk3 in ovaries of domesticated broodstock at 0, 0.5, 1, 3, 6, 12, 24, 48 and $72 \mathrm{hpi}$ of 5-HT (50 $\mu \mathrm{g} / \mathrm{g}$ body weight; 18 -month-old, $N=4$ for each stage). Shrimp injected with $0.85 \%$ saline solution at 0 hpi were included as the vehicle control (VC). Bars labeled with the same letters above the histograms reveal non-significant differences between groups of samples $(\mathrm{P}<0.05)$.

were characterized and 287 spots $(44.70 \%)$ significantly matched protein sequences in the databases $(P<0.05)$. Several reproduction-related proteins, for example, progesterone receptor-related protein p23 (p23), farnesoic- $O$-methyltransferase (FAMeT), cyclophilin A, NADP-dependent leukotriene B4 12- hydroxydehydrogenase (LTB4DH), receptor for activated protein kinase C (RACK), 14-3-3 like protein and several members of ubiquitin-proteosome pathways (e.g. proteosome alpha 3, proteasome beta 6) were identified (Klinbunga et al., 2012). 
The use of 2-DE for proteomic analysis is tedious and time consuming. In addition, it is difficult to identify proteins with very low and high molecular weight or those exhibiting very low or high p/ simultaneously. In the present study, we use a GeLC-MS/MS (Talahkun et al., 2014) for testicular proteome of $P$. monodon. Extracted proteins are electrophoresed through SDSPAGE and further characterized by LC-MS/MS. This speed up the process and more cost-effective than the use of a typical 2-DE for proteomic research. In addition, proteins showing differential expression during testicular development of $P$. monodon could be inferred from the protein spectra. This resolves problems from the inability to achieve quantitative results due to a nonstoichiometric binding of silver ions to proteins based on silver staining (Lopez et al., 2000; Choe and Lee, 2003).

Previously, expression patterns of proteasome alpha 3 subunit (PmPsma3) and proteasome beta 6 (PmPsmb6) mRNAs in domesticated (10-, 14- and 18month-old) and wild broodstock were examined. Results suggested reduced degrees of reproductive maturation of 18-month-old captive males compared to other groups of male broodstock of $P$. monodon (Klinbunga et al., 2012). In the present study, 14- and 18-month-old males were included to identify reproduction-related proteins that showed differential expression in comparison with wild males.

In total, 344 differentially expressed proteins were annotated. Of these, 222 (64.53\%) proteins significantly matched known proteins in the databases Several reproduction-related proteins were identified for example, vasa-like protein, p97/VCP-binding protein p135, Wee1-like protein kinase, serine/threonine protein kinase, mitogen activated protein kinase kinase 2, GTP-binding protein alpha subunit, and members of ubiquitin-proteasome pathways (e.g. ubiquitin-specific peptidase).

The vasa-like protein encodes an ATP-dependent RNA helicase belonging to the DEAD-box family that, in many organisms, is specifically expressed in germline cells throughout the life cycle. Aflalo et al. (2007) characterized the partial cDNA of vasa-like protein in $L$. vannamei and it was only expressed in gonads.

Valosin-containing protein (VCP also known as p97) belongs to the ATPase-associated with diverse cellular activity (AAA) family of ATPase (Bug and Meyer, 2012). In humans, $p 97 / V C P / C d c 48$ has been reported to be required for the mitotic M-phase (Wójcik et al., 2004). The p97/VCP protein is required not only for progression of meiotic metaphase I but also for chromosome condensation at the diakinesis phase in meiotic prophase I (Sasagawa et al., 2007). It functions as a binding protein of sperm-activating and spermattracting factor (SAAF) in eggs of the ascidian (Ciona intestinalis) (Kondoh et al., 2008).

The gonadosomatic index (GSI) values of wild broodstock were greater than those of domesticated broodstock implying a possible reduction of the maturation potential in domesticated shrimp. The expression profiles of proteins found only in wild broodstock may be used as biomarkers for reduced reproductive maturation of $P$. monodon in captivity. In addition, negative or positive effects of the key proteins on the progression of testicular development may also inferred from up- or down-regulated proteins compared between wild and domesticated $P$. monodon. Importantly, the preliminary data on differential expression profiles of key testicular proteins of $P$. monodon should be further confirmed by Western blot analysis or enzyme-linked immunosorbent assay (ELISA).

\section{Expression Levels of Functionally Important Genes in Testes of Wild and Domesticated $P$. monodon}

One difficulty in identifying compounds that stimulate crustacean reproduction is the lack of adequate biological markers for reproductive maturation particularly, in P. monodon. Gene expression and tissue distribution analysis are important and provide the basic information to set up the priority for further analysis of functional genes.

Expression levels of several reproduction-related genes in testes of male wild and domesticated broodstock of $P$. monodon were examined. Prohibitin2 (PmPhb2) showed an increased expression in captive males $(P<0.05)$ while reduced expression levels of meiotic recombination protein DMC1/LIM15 homolog isoform 1 (PmDmc1), cyclophilin A (PmCYA), small ubiquitin modifier 1 (PmSUMO1), spermatogonial stemcell renewal factor, proteasome alpha 3 (PmPsma3) and proteasome beta 6 (PmPsma6) in captive $P$. monodon males were reported $(\mathrm{P}<0.05$; Klinbunga et al., 2012; Leelatanawit et al., 2009).

Protein phosphorylation plays a key role in the signal transduction pathway in most cellular activities including division, proliferation, apoptosis, and differentiation (Hanks et al., 1988; Manning et al., 2002). Srpk3 is member of cell cycle-regulated protein kinases which phosphorylates serine/arginine (SR) domaincontaining proteins in nuclear speckles and mediate the pre-mRNA splicing (Grosso et al., 2008; Jang et al., 2008; Kuroyanagi et al., 1998; Tang et al., 2000). In mammals, SRPK1 and SRPK2 proteins are co-predominantly expressed in testis but highly expressed in pancreas and brain, respectively, whereas SRPK3 is specifically expressed in the heart and skeletal muscle from embryogenesis to adulthood (Bassel-Duby and Olson, 2006; Mylonis and Giannakouros, 2003; Nakagawa et al., 2005; Wang et al., 1998).

A particular gene may express in several tissues and it may possess a different function in different tissues. Tissues distribution analysis of PmSrpk3 were examined in various tissues of a male broodstock and ovaries of a female broodstock. PmSrpk3 was not specifically expressed in gonads but widely expressed in various tissues. This suggested that PmSrpk3 protein may play multifunctional properties in different tissues of $P$. monodon. 
To better understand molecular aspects of the PmSrpk3 gene in reproductive maturation of $P$. monodon, its expression profiles in different groups of male shrimp were examined. The transcriptional levels of differentially expressed genes in testes could be used as the responsive indicators for reproductive maturation of P. monodon. PmSrpk3 mRNA was not significantly different in different groups of domesticated P. monodon males ( $P>0.05)$. Nevertheless, its expression was significantly lower than that of wild broodstock $(P>0.05)$. Expression profiles of testicular PmSrpk3 indicated that reproductive maturation of domesticated male shrimp possibly reduced disregarding the cultivation periods.

\section{Effects of Progesterone and Serotonin (5-HT) Injection on Expression of PmSrpk3}

Understanding the induction mechanisms of reproduction-related genes will be useful in developing effective methodologies for inducing reproductive maturation in P. monodon (Ibara et al., 2007). Progesterone is a sex steroid hormone that plays the important roles in gonad development and maturation (Fingerman, 1997; Miura et al., 2006; Yano, 1985). Progesterone and $17 \alpha$-hydroxyprogesterone injection induced ovarian maturation and spawning in Metapenaeus ensis (Yano, 1985). However, effects of progesterone in reproduction of male shrimp are limited. In this study, effects of progesterone injection on expression of PmSrpk3 transcript were examined. The expression of this gene seemed to be slightly increased from the control in shrimp injected with progesterone for 12,24 and $72 \mathrm{~h}$. However, results were not statistically significant ( $P>0.05)$.

Serotonin (5-HT) has an indirect impact on reproductive maturation by influencing the release of relevant hormones or by modulating the responses of the target tissues to the hormones (Chang et al., 2007; Fingerman, 1992; Sathyanandam et al., 2008). Effects of exogenous serotonin (5-HT) injection on the reproductive performance and maturation of the fiddler crab, Uca pugilator and crayfish, P. clarkii were reported (Sarojini et al., 1993, 1994 and 1995).

The ability to induce reproduction-related genes by exogenous neurotransmitter or steroid hormone administration should reflect an increase in reproductive maturation of male $P$. monodon adults. In the previous study, positive effects of 5-HT injection on the expression of proteasome alpha 3 (PmPsma3) and proteasome beta 6 (PmPsma6) mRNAs in testes of domesticated 18-month-old $P$. monodon were reported. Their expression levels upon injecting with 5-HT for $24 \mathrm{~h}$ were significantly greater than those of the negative and vehicle controls at $0 \mathrm{hpi}(\mathrm{P}>0.05)$ (Klinbunga et al., 2012). In this study, a more rapid effect of inducing gene expression was observed for PmSrpk3 as its expression was significantly increased at $1 \mathrm{~h}$ post injection. Practically, biomarkers to indicate male maturation should be developed based on the non-lethal sampling method. This could be done by further analysis on the expression profiles of PmSrpk3, for example, in hemocytes and pleopods of male $P$. monodon.

In this study, a large number of proteins in testes of $P$. monodon were identified. The differential expression profiles of proteins identified in testes of $P$. monodon implied that these proteins may have contributed testicular development in $P$. monodon. Serotonin administration could induce levels of testicular PmSrpk3 and other reproduction-related transcripts in 18-month-old shrimp. The results suggested that serotonin may be used to promote reproductive maturation of male $P$. monodon. The information on proteomics of testicular proteins allows further studies to resolve problems on reduced reproductive maturation of $P$. monodon in captivity.

\section{References}

Aflalo, E.D., Bakhrat, A., Raviv, S., Harari, D., Sagi, A. \& Abdu, D. (2007). Characterization of a vasa-Like gene from the Pacific white shrimp Litopenaeusvannamei and its expression during oogenesis. Molecular Reproduction and Development 74(2), 172-177.

https://doi.org/10.1002/mrd.20622

Benzie, J.A.H. (1998). Penaeid genetics and biotechnology. Aquaculture, 164(1-4), 23-47.

https://doi.org/10.1016/S0044-8486(98)00175-6

Bassel-Duby, R. \& Olson, E.N. (2006) Signaling pathways in skeletal muscle remodeling. Annual Review of Biochemistry 75, 19-37.

https://doi.org/10.1146/annurev.biochem.75.103004.1 42622

Bug, M., Meyer, H., 2012. Expanding into new markets$\mathrm{VCP} / \mathrm{p} 97$ in endocytosis and autophagy. Journal of Structural Biology 179(2), 76-82. https://doi.org/10.1016/j.jsb.2012.03.003

Chang, C.C., Wu, Z.R. Chen, C.S. Kuo, C.M. \& Cheng, W. (2007). Dopamine modulates the physiological response of the tiger shrimp Penaeus monodon. Aquaculture 270(104), 333-342.

https://doi.org/10.1016/j.aquaculture.2007.04.013

Choe, L.H. \& Lee, K.H. (2003). Quantitative and qualitative measure of intralaboratory two-dimensional protein gel reproducibility and the effects of sample preparation, sample load, and image analysis. Electrophoresis 24, 3500-3507. https://doi.org/10.1002/elps.200305614

Clifford, H.C. \& Preston, N.P. (2006). Genetic improvement, In Operating Procedures for Shrimp Farming. C.E. Boyd, D.E. Jory, G.W. Chamberlain (Eds.). Global Shrimp OP Survey Results and Recommendations (pp. 73-77). Global Aquaculture Alliance, St. Louis, 169 pp.

Coman, G.J., Arnold, S.J., Peixoto, S., Crocos, P.J., Coman, F.E. \& Preston, N.P. (2006). Reproductive performance of reciprocally crossed wild-caught and tank reared Penaeus monodon broodstock. Aquaculture 252(2-4), 372-384.

https://doi.org/10.1016/j.aquaculture.2005.07.028

Fingerman, M. \& Nagabhushanam, R., 1992. Control of the release of crustacean hormones by neuroregulators. Comparative Biochemistry and Physiology, Part C 
Comparatve Pharmacology 102(3), 343-352. https://doi.org/10.1016/0742-8413(92)90125-Q

Fingerman, M., Nagabhushanam, R. \& Sarojini, R. (1993). Vertebrate-type hormones in crustaceans: localization, identification and functional significance. Zoological Science 10, 13-29.

Grosso, A.R., Gomes, A.Q., Barbosa-Morais, N.L., Caldeira S, Thorne, N.P., Grech, G., von Lindern, M. \& CarmoFonseca, M. (2008) Tissue-specific splicing factor gene expression signatures. Nucleic Acids Research 36(15), 4823-4832. https://doi.org/10.1093/nar/gkn463

Hanks, S.K., Quinn, A.M. \& Hunter, T. (1988). The protein kinase family: conserved features and deduced phylogeny of the catalytic domains. Science 241(4861), 42-52. https://doi.org/10.1126/science. 3291115

Ibara, A.M., Racotta, I.S., Arcos, F.G. \& Palacios, E., 2007. Progress on the genetics of reproductive performance in penaeid shrimp. Aquaculture 268(1-4), 23-43. https://doi.org/10.1016/j.aquaculture.2007.04.028

Jang, S.W., Yang, S-J., Ehlén, A., Dong, S. Khoury, H., Chen, J., Persson, J.L. \& Ye, K. (2008). Serine/arginine proteinspecific kinase 2 promotes leukemia cell proliferation by phosphorylating acinus and regulating cyclin A1. Cancer Research 68 (12), 4559-4570.

https://doi.org/10.1158/0008-5472.CAN-08-0021

Johansson, C., Samskog, J., Sundstrom, L., Wadensten, H. \& Bjorkesten, L. (2006). Differential expression analysis of Escherichia coli proteins using a novel software for relative quantitation of LC-MS/MS data. Proteomics 6(16), 4475-4485.

https://doi.org/10.1002/pmic.200500921

Klinbunga, S., Siludjai, D., Wuthijinda, W., Tassanakajon, A., Jarayabhand, P. \& Menasveta, P. (2001). Genetic heterogeneity of the giant tiger shrimp (Penaeus monodon) in Thailand revealed by RAPD and mtDNARFLP analyses. Marine Biotechnology 3(5), 428-438. https://doi.org/10.1007/s10126-001-0055-9

Klinbunga, S., Petkorn, S., Kittisenachai, S., Phaonakrop, N., Roytrakul, S., Khamnamtong, B. \& Menasveta, P. (2012). Identification of reproduction-related proteins and characterization of proteasome alpha 3 and proteasome beta 6 cDNAs in testes of the giant tiger shrimp Penaeus monodon Molecular and Cellular Endocrinology 355(1), 143-152. https://doi.org/10.1016/j.mce.2012.02.005

Kondoh, E., Konno, A., Inaba, K., Oishi, T., Murata, M. \& Yoshida, M. (2008). Valosin-containing protein/p97 interacts with sperm-activating and sperm-attracting factor (SAAF) in the ascidian egg and modulates spermattracting activity. Development, Growth \& Differentiation 50(8), 665-673.

https://doi.org/10.1111/j.1440-169X.2008.01064.x

Kuroyanagi, N., Onogi, H., Wakabayashi, T. \& Hagiwara, M. (1998). Novel SR-protein-specific kinase, SRPK2, disassembles nuclear speckles. Biochemical and Biophysiccal Research Communications 242(2), 357364. https://doi.org/10.1006/bbrc.1997.7913

Laemmli, U.K. (1970). Cleavage of structural proteins during the assembly of the head of bacteriophage T4. Nature 227, 680-685. https://doi.org/10.1038/227680a0

Leelatanawit, R., Klinbunga, S., Puanglarp, N., Tassanakajon, A., Jarayabhand, P., Hirono, I., Aoki, T. \& Menasveta, P., 2004. Isolation and characterization of differentially expressed genes in ovaries and testes of the giant tiger shrimp (Penaeus monodon). Marine Biotechnology 6, S506-S510.
Leelatanawit, R., Klinbunga, S., Hirono, I., Aoki, T. \& Menasveta, P., 2008. Suppression subtractive hybridization ( $\mathrm{SSH}$ ) for isolation and characterization of genes related with testicular development of the giant tiger Penaeus monodon. BMB Reports 41, 796-802.

Leelatanawit, R., Sittikankeaw, K., Yocawibun, P., Klinbunga, S., Hirono, I., Aoki, T., Menasveta P., 2009. Identification, characterization and expression of sex-related genes in testes of the giant tiger shrimp Penaeus monodon. Comparative Biochemistry and Physiology Part A: Molecular \& Integrative Physiology 152(1), 66-76. https://doi.org/10.1016/j.cbpa.2008.09.004

Leelatanawit, R., Uawisetwathana, U., Klanchui, A., Khudet, J., Phomklad, S., Wongtriphop, S., Jiravanichpaisal, P. \& Karoonuthaisiri, N. (2017). Transcriptomic analysis of male black tiger shrimp (Penaeus monodon) after polychaete feeding to enhance testicular maturation. Marine Biotechnology 19, 125-135.

https://doi.org/10.1007/s10126-017-9738-8

Lopez, M.F., Berggren, K., Chernokalskaya, E., Lazarev, A., Robinson, M. \& Patton, W.F. (2000). A comparison of silver stain and SYPRO Ruby protein gel stain with respect to protein detection in two-dimensional gels and identification by peptide mass profiling. Electrophoresis 21, 3673-3683. https://doi.org/10.1002/15222683(200011)21:17<3673::AID-ELPS3673>3.0.CO;2-M

Makinouchi, S. \& Hirata, H. (1995). Studies on maturation and reproduction of pond-reared Penaeus monodon for developing a closed-cycle culture system. Israeli Journal of Aquaculture-Bamidgeh 47, 68-77.

Manning, G., Plowman, G.D., Hunter, T. \& Sudarsanam, S. (2002). Evolution of protein kinase signaling from yeast to man. Trends Biochem Sci. 2002 27(10), 514-520. https://doi.org/10.1016/S0968-0004(02)02179-5

Miura, T., Higuchi, M., Ozaki, Y., Ohta, T. \& Miura, C. (2006). Progestin is an essential factor for the initiation of the meiosis in spermatogenetic cells of the eel. Proceedings of the National Academy of Sciences of the United States of America 103, 7333-7338. www.pnas.orgcgidoi10.1073pnas.0508419103

Mylonis, I. \& Giannakouros, T. (2003). Protein kinase CK2 phosphorylates and activates the SR protein-specific kinase 1. Biochemical and Biophysiccal Research Communications 301(3), 650-656. https://doi.org/10.1016/S0006-291X(02)03055-3

Nakagawa, O., Arnold, M., Nakagawa, M., Hamada, H., Shelton, J.M., Kusano, H., Harris, T.M., Childs, G., Campbell, K.P., Richardson, J.A., Nishino, I., \& Olson, E.N. (2005) Centronuclear myopathy in mice lacking a novel muscle-specific protein kinase transcriptionally regulated by MEF2. Genes \& Development 19(17), 20662077. http://www.genesdev.org/cgi/doi/10.1101/ gad.1338705

Perkins, D.N., Pappin, D.J., Creasy, D.M. \& Cottrell, J.S. (1999). Probability-based protein identification by searching sequence databases using mass spectrometry data. Electrophoresis 20(18), 3551-3567. https://doi.org/10.1002/(sici)15222683(19991201)20:18<3551::aid-elps3551>3.0.c0;2-2

Peterson, P.L. (1977). A simplification of the protein assay method of Lowry et al. which is more generally applicable. Analytical Biochemistry 83(2), 346-356. https://doi.org/10.1016/0003-2697(77)90043-4

Preechaphol, R., Leelatanawit, R., Sittikankeaw, K., Klinbunga, S., Khamnamtong, B., Puanglarp, N. \& Menasveta, P. 
(2007). Expressed sequence tag analysis for identification and characterization of sex-related genes in the giant tiger shrimp Penaeus monodon. Journal of Biochemistry and Molecular Biology 40(4), 501-510. https://doi.org/10.5483/bmbrep.2007.40.4.501.

Rosenberry, B. (2003). World shrimp farming 2003. Shrimp News International, San Diego, California.

Sarojini, R., Nagabhushanam, R. \& Fingerman, M. (1993). In vivo evaluation of 5 - hydroxytryptamine stimulation of the testes in the fiddler crab, Uca pugilator: a presumed action on the neuroendocrine system. Comparative Biochemistry and Physiology Part C: Pharmacology, Toxicology and Endocrinology 106(2), 321-325. https://doi.org/10.1016/0742-8413(93)90140-G

Sarojini, R., Nagabhushanam, R. \& Fingerman, M. (1994). 5Hydroxytryptaminergic control of testes development through the androgenic gland in the red swamp crayfish, Procambarus clarkii. Invertebrrate Reproduction \& Development 26(2), 127-132. https://doi.org/10.1080/07924259.1994.9672409

Sarojini, R., Nagabhushanam, R. \& Fingerman, M. (1995). Mode of action of the neurotransmitter 5hydroxytryptamine in stimulating ovarian maturation in the red swamp crayfish, Procambarus clarkii: an in vivo and in vitro study. Journal of Experimental Zoology 271 (5), 395-400. https://doi.org/10.1002/jez.1402710509

Sasagawa, Y., Yamanaka, K., Nishikori, S. \& Ogura, T. (2007). Caenorhabditis elegans p97/ CDC-48 is crucial for progression of meiosis I. Biochemical and Biophysical Research Communications 358(3), 920-924. https://doi.org/10.1016/j.bbrc.2007.05.022.

Sathyanandam, S., Vasudevan, S. \& Natesan, M. (2008). Serotonin modulation of hemolymph glucose and crustacean hyperglycemic hormone titers in Fenneropenaeus indicus. Aquaculture 281(1-4), 106-112. https://doi.org/10.1016/j.aquaculture.2008.06.003

Talakhun, W., Phaonakrop, N., Roytrakul, R., Klinbunga, S., Menasveta, P. \& Khamnamtong, B. 2014. Proteomic analysis of ovarian proteins and characterization of thymosin- $\beta$ and RAC-GTPase activating protein 1 of the giant tiger shrimp Penaeus monodon. Comparative Biochemistry and Physiology Part D: Genomics and Proteomics 11, 9-19. https://doi.org/10.1016/j.cbd.2014.05.002

Tang, Z., Kuo, T., Shen, J. \& Lin, R.-J., (2000). Biochemical and genetic conservation of fission yeast Dsk1 and human SR protein-specific kinase 1. Molecular and Cellular Biology 20(3), 816-824. https://doi.org/10.1128/mcb.20.3.816824.2000 .
Thorsell, A., Portelius, E., Blennow, K. \& Westman, B.A. (2007). Evaluation of sample fractionation using microscale liquid-phase isoelectric focusing on mass spectrometric identification and quantitation of proteins in a SILAC experiment. Rapid Communications in Mass Spectrometry 21(5), 771-778.

https://doi.org/10.1002/rcm.2898

Uengwetwanit, T., Ponza, P., Sangsrakru, D., Wichadakul, D., Ingsriswang, S., Leelatanawit, R., Klinbunga, S., Tangphatsornruang, S. \& Karoonuthaisiri, N. (2018). Transcriptome-based discovery of pathways and genes related to reproduction of the black tiger shrimp (Penaeus monodon). Marine Genomics. 37, 69-73. https://doi.org/10.1016/j.margen.2017.08.007

Wang, H.Y., Lin, W., Dyck, J.A., Yeakley, J.M., Songyang, Z., Cantley, L.C. \& Fu, D. (1998). SRPK2: a differentially expressed SR protein-specific kinase involved in mediating the interaction and localization of pre-mRNA splicing factors in mammalian cells. Journal of Cell Biology 140(4), 737-750.

https://doi.org/10.1083/jcb.140.4.737

Withyachumnarnkul, B., Boonsaeng, V., Flegel, T. W., Panyim, S., Wongteerasupaya C., 1998. Domestication and selective breeding of Penaeus monodon in Thailand, in: Proceedings to the Special Session on Advances in Shrimp Biotechnology, T. Felgel (Ed.), The Fifth Asian Fisheries Forum: International Conference on Fisheries and Food Security Beyond the Year 2000. 11-14 November 1998. Chiengmai, Thailand, pp. 73-77.

Wójcik, C., Yano, M. \& DeMartino, G.N. (2004). RNA interference of valosin-containing protein (VCP/p97) reveals multiple cellular roles linked to ubiquitin/proteasome-dependent proteolysis. Journal of Cell Science 117, 281-292. https://doi.org/10.1242/jcs.00841

Wongsurawat, T., Leelatanawit1, R., Thamniemdee, N., Uawisetwathana, U., Karoonuthaisiri, N., Menasveta, P. \& Klinbunga, S. (2010). Identification of testis-relevant genes using in silico analysis from testis ESTs and cDNA microarray in the black tiger shrimp (Penaeus monodon) BMC Molecular Biology 11, 55.

http://www.biomedcentral.com/1471-2199/11/55

Yano, I. (1985) Induced ovarian maturation and spawning in greasyback shrimp, Metapenaeus ensis, by progesterone. Aquaculture 47, 223-229. https://doi.org/10.1016/0044-8486(85)90068-7 